\title{
Preparação, caracterização e análise sensorial de pão integral enriquecido com farinha de subprodutos do mamão
}

\author{
Preparation, characterization and sensory analysis of whole bread enriched with \\ papaya byproducts flour
}

\author{
Cláudia Mendes dos Santos ${ }^{1}$, Denise Alvarenga Rocha ${ }^{1 *}$, Raul Antônio Viana Madeira², \\ Estela de Rezende Queiroz' ${ }^{1}$, Marcelle Mendes Mendonça' ${ }^{2}$, Joelma Pereira ${ }^{2}$, Celeste Maria Patto de Abreu ${ }^{1}$ \\ 1 Universidade Federal de Lavras (UFLA), Departamento de Química, Lavras/MG - Brasil \\ 2 Universidade Federal de Lavras (UFLA), Departamento de Ciência dos Alimentos, Lavras/MG - Brasil
}

\section{*Corresponding Author}

Denise Alvarenga Rocha, Universidade Federal de Lavras (UFLA), Departamento de Química, Campus Universitário, Caixa Postal: 3037, CEP: 37200-000, Lavras/MG - Brasil, e-mail: deniserocha3@hotmail.com

Cite as: Preparation, characterization and sensory analysis of whole bread enriched with papaya byproducts flour. Braz. J. Food Technol., v. 21, e2017120, 2018.

Received: Aug. 02, 2017; Accepted: Nov. 24, 2017

\section{Resumo}

Devido ao processamento industrial do mamão, uma grande quantidade de subprodutos dessa fruta é gerada. Dentre esses subprodutos, estão as cascas e sementes, que têm grande valor nutricional, pois apresentam valores consideráveis de fibras, proteínas e antioxidantes. O objetivo, neste estudo, foi desenvolver um pão de fôrma integral adicionado de farinha mista, proveniente das cascas e sementes do mamão da cultivar Havaí. Na elaboração do pão de fôrma integral, foi adicionada farinha mista (casca e semente) em diferentes concentrações (0\%,3\%,6\% e 9\%), na proporção de $70 \%$ de farinha da casca e $30 \%$ da farinha da semente do mamão. A adição da farinha mista resultou em produtos com elevados

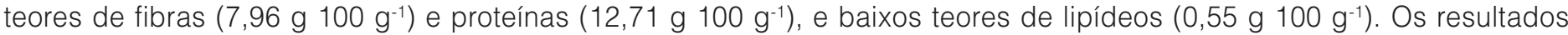
da análise sensorial mostraram que a fabricação do pão com 3\% de adição da farinha mista resultou em boa aceitação, quando comparado com o controle. Assim, a adição da farinha dos subprodutos do mamão na fabricação de pães é uma boa alternativa para compor a dieta da população, por ser nutricionalmente rico em fibras e proteínas.

Palavras-chave: Derivados do mamão; Panificação; Composição química; Fibra alimentar.

\section{Abstract}

Due to the industrial processing of papaya, a great amount of byproducts from this fruit is generated. The peel and seeds are amongst these byproducts and have great nutritional value, since they present considerable amounts of fibre, lipids, proteins and antioxidants. The objective of this study was to develop whole wheat bread loaves with the addition of a mixed flour made from the peel and seeds of papayas of the Hawaiian cultivar. In the whole-grain breadmaking process, the mixed flour (peel and seeds) was added in different concentrations ( $0 \%, 3 \%, 6 \%$ and $9 \%$ ), in the proportion of $70 \%$ of papaya peel flour to $30 \%$ of papaya seed flour. The addition of the mixed flour resulted in products with high fibre $\left(7.96 \mathrm{~g}^{\left.100 \mathrm{~g}^{-1}\right)}\right.$

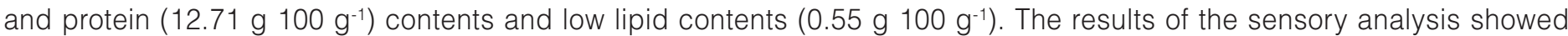
that the bread made with the addition of $3 \%$ of the mixed flour resulted in good acceptance when compared to the control. Thus the addition of papaya byproducts flour in the manufacture of bread is a good alternative for the diet of the population, since it is nutritionally rich in fibre and protein.

Keywords: Papaya derivatives; Baking; Chemical composition; Dietary fibre. 


\section{Introdução}

A indústria de alimentos, em especial a de processamento de frutos, produz uma grande quantidade de resíduos agroindustriais. De acordo com a variedade, esses resíduos constituem $65-70 \%$ da massa total dos frutos. Uma alternativa que vem se destacando é o aproveitamento de subprodutos como matéria-prima para a produção de alimentos diferenciados e que estes sejam incluídos na alimentação humana (UCHÔA THOMAZ et al., 2014). Agregar valor a estes subprodutos é de grande interesse, pois eles são fontes de nutrientes e fibras (STORCK et al., 2013). Durante o processamento industrial do mamão, são retiradas cascas e sementes, e uma grande quantidade de resíduos ou subprodutos dessa fruta é gerada, constituindo cerca de $50 \%$ da mesma (PORTE et al., 2011; VENTURINI et al., 2012).

Devido ao seu amplo consumo, o pão mostra-se como alternativa interessante para a utilização de subprodutos do processamento de frutas, visando aumentar sua composição nutricional, principalmente com o enriquecimento em fibras e proteínas. Contudo, a quantidade e a qualidade desses subprodutos incorporados aos alimentos tradicionais devem ser cuidadosamente avaliadas (MAIA et al., 2015).

Um constituinte importante encontrado nos pães integrais é a fibra alimentar. Assim, o aproveitamento de subprodutos agroindustriais de frutas, ricos em fibra, poderia acrescentar nutrientes e inovação em formulações de panificação. Dietas ricas em fibras geram efeitos benéficos à saúde, pois estas têm grande importância no metabolismo da glicose e de lipídeos (FIGUEIREDO et al., 2009). Observa-se que somente a polpa do mamão é consumida e o restante do fruto, casca e sementes, rejeitado, e que esses subprodutos podem servir como elementos de estudos em utilizações alternativas. Assim, a proposta, neste trabalho, foi avaliar a potencialidade da farinha de casca e semente do mamão como ingrediente no desenvolvimento de pão de fôrma integral e suas implicações tecnológicas, nutricionais e sensoriais.

\section{Material e métodos}

Os frutos de mamão cultivar Havaí foram adquiridos no CEASA/MG. Selecionaram-se 24 frutos maduros, sendo estes lavados, sanitizados (solução de hipoclorito de sódio 200 ppm) e descascados. As cascas foram cortadas e as sementes, retiradas e lavadas com água corrente para retirada de mucilagem. As cascas e as sementes foram espalhadas em bandejas e secas em estufa de circulação de ar, a $45^{\circ} \mathrm{C}$, com revolvimento do material durante quatro dias. Após a secagem, as amostras foram trituradas em moinho TECNAL (TE-631), obtendo-se uma fina farinha. A farinha da casca do mamão (FCM) e a farinha da semente do mamão (FSM) foram utilizadas na elaboração de pães de fôrma integrais (PFI). A formulação base do pão de fôrma integral utilizada neste experimento está apresentada na Tabela 1. Foi adicionada farinha mista (FM) em diferentes concentrações (0\%, 3\%, 6\% e 9\%). A FM foi composta de $70 \%$ de FCM e $30 \%$ da FSM, com base no rendimento de farinha encontrado nos frutos de mamão. Os pães de fôrma integrais foram produzidos separando-se e pesando-se as farinhas de acordo com cada proporção de adição de farinha mista. As farinhas foram colocadas na masseira G-Paniz AE 25, a 40 rpm, misturando-se com os demais ingredientes: sal, açúcar mascavo, gordura vegetal, reforçador e fermento biológico.

Adicionou-se a água gelada até a proporção indicada e bateu-se até o desenvolvimento máximo do glúten (ponto de véu). A massa foi dividida e cortada em pedaços de $250 \mathrm{~g}$, boleada, modelada na modeladora de pães G-Paniz MPS 350 e colocada em fôrmas retangulares de $19,5 \mathrm{~cm} \times 8,0 \mathrm{~cm} \times 4,5 \mathrm{~cm}$, sem tampa. A fermentação ocorreu em câmara de fermentação Klimaquip CFCK-20, estabilizada a $27^{\circ} \mathrm{C}$ e $80 \%$ de umidade relativa, por duas horas. Em seguida, os pães foram submetidos ao forneamento, em forno turbo Pratica Technicook E-125 Technical, a $180{ }^{\circ} \mathrm{C}$, sem vapor, por 20 minutos. Após a produção, os pães foram resfriados em temperatura ambiente, por duas horas, e embalados em sacos de polietileno até o início dos testes sensoriais, que ocorreram 24 horas após a sua elaboração.

Os pães de fôrma integrais preparados com diferentes percentagens de FM foram avaliados sensorialmente pelo teste de aceitação, utilizando-se uma escala hedônica de 1 a 9 pontos, em que 1 correspondeu a "desgostei extremamente" e 9, a "gostei extremamente", considerando o quanto gostaram ou desgostaram de cada amostra de pão em relação a aroma, textura, sabor e impressão global. A intenção de compra foi avaliada por meio de escala estruturada mista, variando de "1-certamente eu não compraria" a "5-certamente eu compraria".

Tabela 1. Formulação dos pães de fôrma integrais.

\begin{tabular}{lcc}
\multicolumn{1}{c}{ Ingredientes } & $\begin{array}{c}\text { Quantidade } \\
(\mathbf{g})\end{array}$ & $\begin{array}{c}\text { Porcentagem } \\
(\mathbf{\%})^{*}\end{array}$ \\
\hline Farinha de trigo branca & 500 & 5 \\
Farinha de trigo integral & 500 & 5 \\
Farinha mista & $0 ; 45,3 ; 93,0 ;$ & $0 ; 3 ; 6 ; 9$ \\
(casca/semente de mamão) & 143,2 & 2 \\
Sal refinado iodado & 20 & 2 \\
Açúcar mascavo & 20 & 2 \\
Gordura vegetal & 20 & 3 \\
Fermento biológico & 30 & 63 \\
Água & 630 & \\
Reforçador de massa & & 1 \\
(reforçador de & 10 & \\
glúten+enzimas+emulsificante) & & \\
\hline
\end{tabular}

*Os percentuais dos ingredientes se referem a quantidade de farinha de trigo branca e farinha de trigo integral. 
Para a avaliação das amostras, um quarto da fatia do pão de fôrma integral foi servido segundo Wakeling e MacFie (1995). A aceitação dos pães de fôrma integrais foi avaliada por meio de um grupo de 100 provadores não treinados, utilizando-se o teste afetivo, após terem sido informados sobre os termos da pesquisa, sendo esta avaliada e aprovada previamente pelo Comitê de Ética em Pesquisa com Seres Humanos da UFLA, com o número de certificado de apresentação para apreciação ética (CAAE): 20407313.5.0000.5148.

O PFI contendo a FM que apresentou a melhor aceitação e aquele sem a FM foram submetidos às análises físicas (volume, perda de massa, densidade, textura e cor) e químicas (composição proximal e mineral, pH, acidez titulável e compostos fenólicos). Os pães foram congelados em freezer, a $-17{ }^{\circ} \mathrm{C}$, até a realização das análises. Foram produzidas e utilizadas, nas análises físicas e químicas, e na análise sensorial, 15 unidades de PFI de cada formulação.

O volume dos pães e o volume específico foram determinados de acordo com Kajishima et al. (2001). A avaliação da perda de massa do produto e a densidade foram calculadas segundo Ferreira et al. (2001).

Na determinação de textura, foi utilizado o texturômetro TA.XT plus (Stable Micro Systems, UK), avaliando-se o perfil de textura relacionado à firmeza, segundo Association of Official Analytical Chemists (LATIMER JUNIOR, 2012) com modificações. Utilizaram-se seis repetições (seis fatias) por tratamento. A determinação de cor foi realizada em aparelho colorimétrico marca Konica Minolta, modelo CM-5, e os resultados foram expressos em valores de L, $a^{*}$ e b* pelo sistema CieLab (GENNADIOS et al., 1996).

A composição proximal e o pH foram determinados pela metodologia descrita pela AOAC (LATIMER JUNIOR, 2012). A acidez titulável foi determinada de acordo com o Instituto Adolfo Lutz (IAL, 2005) e os resultados obtidos foram expressos em percentagem de ácido cítrico.

O cálculo do valor calórico dos PFI foi realizado utilizando-se os coeficientes de ATWATER (carboidratos = 4,0; lipídios = 9,0; proteínas $=4,0$ ).

Para quantificar os minerais ( $\mathrm{Ca}, \mathrm{P}, \mathrm{K}, \mathrm{Mg}, \mathrm{S}, \mathrm{Cu}$, $\mathrm{Mn}, \mathrm{Zn}$, Fe e $\mathrm{Na}$ ), o P e o S, foi utilizada a técnica da colorimetria, sendo Na e K por fotometria de chama, e Ca, Mg, Cu, Mn, Zn e Fe por espectrofotometria de absorção atômica (MALAVOLTA et al., 1997).

A extração dos compostos fenólicos dos PFI foi realizada com metanol 50\% (1:25, p/v) e estes foram dosados utilizando-se o Reagente de Folin-Denis (LATIMER JUNIOR, 2012).

Para a análise sensorial, foi utilizado delineamento inteiramente casualizado (DIC) com quatro tratamentos (quatro concentrações) e 100 provadores. Na escolha dos melhores pães, os dados sensoriais foram submetidos à análise de componentes principais. As análises estatísticas foram realizadas utilizando-se os procedimentos do programa estatístico Senso Maker (PINHEIRO et al., 2013). Para as análises físicas e químicas dos pães, utilizou-se o delineamento experimental inteiramente casualizado (DIC), em esquema fatorial com dois tratamentos (duas concentrações) e seis repetições (seis pães).

Os resultados da análise sensorial e das análises físicas e químicas foram submetidos à análise de variância por meio do programa computacional R (R CORE TEAM, 2013), sendo as médias comparadas pelo Teste Tukey, a $5 \%$ de probabilidade.

\section{Resultados e discussão}

Na Tabela 2, apresentam-se as notas de aceitação dadas pelos provadores para as características aroma, textura, sabor, impressão global e intenção de compra dos pães de fôrma integrais. Para aroma, não houve diferença significativa entre os tratamentos P1 e P2, e entre P3 e P4. O pão adicionado com farinha mista P2 teve o mesmo patamar de aceitação, em relação ao pão sem a farinha mista, quanto ao aroma.

Os pães P1 e P2, e P3 e P4 apresentaram aceitação diferente em relação a sabor, sendo as médias das notas dadas situadas entre conceitos: gostei moderadamente (7) e gostei ligeiramente (6), sendo P1 e P2 os mais aceitos neste quesito. Para o atributo textura, não houve diferença significativa entre os tratamentos P3 e P4, e estes diferiram dos demais. Para impressão global, os pães dos tratamentos $\mathrm{P} 1$ e P2 receberam notas de aceitação maiores que os demais tratamentos, equivalentes a gostei moderadamente (7) e gostei ligeiramente (6), tendo todos

Tabela 2. Notas de aceitação dos atributos aroma, textura, sabor, impressão global e intenção de compra dos pães de fôrma integrais com adição de farinha de derivados do mamão.

\begin{tabular}{cccccc} 
Tratamento $^{1}$ & Aroma & Textura & Sabor & Impressão global & $\begin{array}{c}\text { Intenção de } \\
\text { compra }\end{array}$ \\
\hline P1 & $7,22^{a}$ & $7,72^{a}$ & $7,36^{a}$ & $7,59^{a}$ & $4,22^{a}$ \\
P2 & $6,79^{a}$ & $6,52^{\mathrm{b}}$ & $6,36^{\mathrm{b}}$ & $6,55^{\mathrm{b}}$ & $3,51^{\mathrm{b}}$ \\
P3 & $6,14^{\mathrm{b}}$ & $5,76^{\mathrm{c}}$ & $5,14^{\mathrm{c}}$ & $5,57^{\mathrm{c}}$ & $2,6^{\mathrm{c}}$ \\
P4 & $5,91^{\mathrm{b}}$ & $5,29^{\mathrm{c}}$ & $4,24^{\mathrm{d}}$ & $4,79^{\mathrm{d}}$ & $2,2^{\mathrm{d}}$ \\
\hline
\end{tabular}

Médias seguidas pela mesma letra, na coluna, não diferem entre si pelo Teste Tukey, a 5\% de probabilidade ( $\mathrm{n}=100$ ); ${ }^{1} \mathrm{P} 1$ - controle; P2 - pão com adição de 3\% de farinha mista (FM); P3 - pão com 6\% de adição de FM; P4 - pão com adição de 9\% de FM. 
os pães apresentado diferença significativa. Em relação à intenção de compra, os PFI diferiram entre si e os que apresentaram maiores notas foram o sem adição de farinha mista (P1) e o com adição de 3\% de farinha mista (P2), com notas médias que equivalem a provavelmente compraria (4) e talvez compraria (3).

$\mathrm{Na}$ análise sensorial de pães de fôrma elaborados com a polpa e a casca de baru, com a finalidade de aumentar os teores de nutrientes, principalmente fibras, Rocha e Cardoso Santiago (2009) apresentaram as notas para os atributos textura $(6,07$ a 7,15$)$, sabor $(6,67$ a 7,27$)$ e impressão global $(7,3$ a 7,5$)$ próximas às observadas nos pães de fôrma integrais P1 e P2 do presente trabalho.

O mapa de preferência interno foi efetuado utilizando-se os dados obtidos no teste de aceitação com escala de aroma, textura, sabor, impressão global e intenção de compra das quatro amostras de pães de fôrma integral. Na Figura 1, observa-se a dispersão das amostras (P1, P2, P3, P4), bem como a dispersão dos provadores no espaço bidimensional, representada pelos dois componentes principais. Os pães mais aceitos, em todas as características (A, B, C, D), foram o P1 e o P2. Pode-se observar que todos os atributos analisados influenciaram a separação dos pães P1 e P2, uma vez que há um grande número de consumidores (vetores) em direção a estas amostras. A maior preferência por estes pães pode ser atribuída às maiores notas para os atributos aroma, textura, sabor, impressão global e intenção de compra (Tabela 2). Portanto, as análises físicas e químicas foram realizadas no controle P1 e nos pães P2.

Em relação à composição proximal das farinhas utilizadas na elaboração dos pães de fôrma integrais, destaca-se o elevado teor de fibras alimentares presente na farinha da casca do mamão $\left(33,05 \mathrm{~g} 100 \mathrm{~g} \mathrm{~g}^{-1}\right)$. Este resultado mostra a importância da casca como fonte de fibra alimentar, uma vez que, de acordo com a ANVISA (BRASIL, 2012), um alimento com teor de 6\% pode ser considerado com alto teor de fibra. Na farinha da casca do mamão, a maior proporção de fibra é do tipo insolúvel $\left(26,10 \mathrm{~g} 100 \mathrm{~g}^{-1}\right)$, fibras estas que são parcialmente fermentadas, aceleram o trânsito intestinal e aumentam a massa fecal. Já a farinha da semente do mamão se

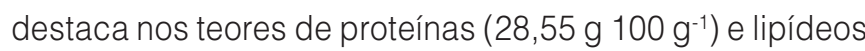
$\left(29,72 \mathrm{~g}^{\left.100 \mathrm{~g}^{-1}\right)}\right.$ (SANTOS et al., 2014).

As características químicas, físicas e físico-químicas dos pães foram avaliadas apenas em P1 e P2, que foram os tratamentos que tiveram maior aceitabilidade. A determinação de umidade do alimento é muito importante,
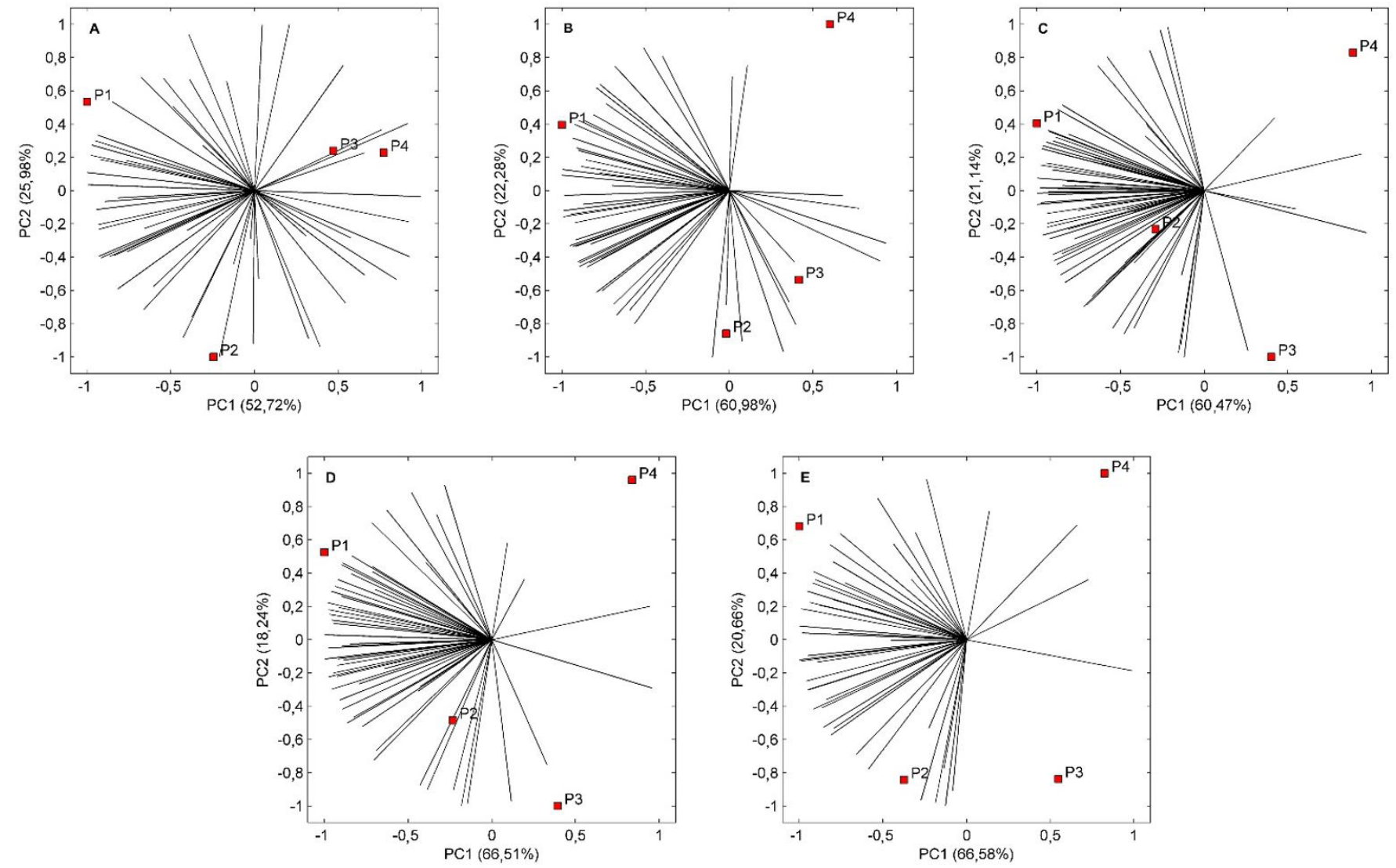

Figura 1. Mapa de Preferência Interno para as amostras de pães de fôrma integral em relação a aroma (A), textura (B), sabor (C), impressão global (D) e intenção de compra (E). P1 - controle; P2 - pão com adição de 3\% de farinha mista (FM); P3 - pão com 6\% de adição de FM; P4 - pão com adição de 9\% de FM. 
pois é o principal fator para o desenvolvimento de fungos, leveduras e bactérias.

Apesar de P1 não diferir estatisticamente de P2 (Tabela 3), houve uma tendência de maior umidade no P1. Na literatura, encontram-se pães elaborados com subprodutos agroindustriais com diferentes teores de umidade, em g $100 \mathrm{~g}^{-1}$, variando de 32,67 a 35,3, em pães com casca e polpa de baru (ROCHA; CARDOSO SANTIAGO, 2009); 9,6, em pães elaborados com casca de mandioca (VILHALVA et al., 2011) e de 35,5, com uso de farinha de quinoa na fabricação de pães de fôrma (BORGES et al., 2013). Essa variação, certamente, é devida aos componentes utilizados na preparação dos pães. O teor elevado de umidade em pães aumenta a atividade microbiana, deixando o produto grudento e borrachudo, e altera sua textura, sendo este um dos fatores responsáveis pela perda da qualidade do produto (OLIVEIRA et al., 2011).

Com relação às cinzas, às fibras insolúveis, aos carboidratos e ao valor calórico, não houve diferença significativa entre os pães analisados, P1 e P2 (Tabela 3). Borges et al. (2013) registraram, em pães de fôrma elaborados com farinha mista de trigo e quinoa, teores de

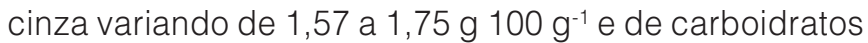

Tabela 3. Valores médios da composição proximal, pH, acidez titulável, compostos fenólicos e valor calórico dos pães de fôrma integrais com adição de farinha de derivados do mamão.

\begin{tabular}{|c|c|c|}
\hline Parâmetros & P1 ${ }^{1}$ & $\mathbf{P 2}^{2}$ \\
\hline $\begin{array}{l}\text { Umidade } \\
\left(\mathrm{g}_{\left.100 \mathrm{~g}^{-1}\right)}\right.\end{array}$ & $35,77 \pm 2,19$ & $33,66 \pm 3,27$ ns \\
\hline $\begin{array}{l}\text { Extrato etéreo } \\
\left(\mathrm{g}_{\left.100 \mathrm{~g}^{-1}\right)}\right.\end{array}$ & $1,19 \pm 0,10^{a}$ & $0,55 \pm 0,17^{b}$ \\
\hline $\begin{array}{l}\text { Proteína } \\
\left(\mathrm{g} 100 \mathrm{~g}^{-1}\right)\end{array}$ & $12,58 \pm 0,05 b$ & $12,71 \pm 0,03^{a}$ \\
\hline $\begin{array}{l}\text { Fibra insolúvel } \\
\qquad\left(\mathrm{g} 100 \mathrm{~g}^{-1}\right)\end{array}$ & $5,33 \pm 1,08$ & $6,59 \pm 0,81 \mathrm{~ns}$ \\
\hline $\begin{array}{l}\text { Fibra solúvel } \\
\left(\text { g } 100 \mathrm{~g}^{-1}\right)\end{array}$ & $0,51 \pm 0,14^{b}$ & $1,37 \pm 0,44^{a}$ \\
\hline 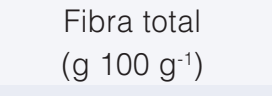 & $5,84 \pm 0,97^{b}$ & $7,96 \pm 0,43 a$ \\
\hline 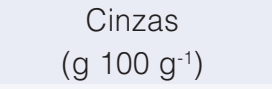 & $1,99 \pm 0,09$ & $2,11 \pm 0,12^{\mathrm{ns}}$ \\
\hline $\begin{array}{l}\text { Carboidrato } \\
\left(\mathrm{g}_{\left.100 \mathrm{~g}^{-1}\right)}\right.\end{array}$ & $40,63 \pm 1,34$ & $42,01 \pm 3,23 \mathrm{~ns}$ \\
\hline $\begin{array}{l}\text { Valor calórico } \\
\left(\text { kcal } 100 \mathrm{~g}^{-1}\right)\end{array}$ & $223,56 \pm 5,21$ & $223,85 \pm 14,34$ ns \\
\hline $\mathrm{pH}$ & $5,65 \pm 0,03^{a}$ & $5,57 \pm 0,01^{b}$ \\
\hline $\begin{array}{l}\text { Acidez titulável } \\
\quad\left(\mathrm{g} 100 \mathrm{~g}^{-1}\right)\end{array}$ & $0,20 \pm 0,01^{b}$ & $0,47 \pm 0,02^{a}$ \\
\hline $\begin{array}{l}\text { Composto fenólico } \\
\left(\mathrm{mg} 100 \mathrm{~g} \mathrm{~g}^{-1}\right)\end{array}$ & $43,37 \pm 2,35^{b}$ & $92,40 \pm 2,13^{a}$ \\
\hline
\end{tabular}

ns_ não significativo, a $5 \%$ de probabilidade $(n=6) ;{ }^{1} P 1$ - controle; ${ }^{2} \mathrm{P} 2$ - pão com adição de $3 \%$ de farinha mista (FM) variando de 40,54 a 43,74 g $100 \mathrm{~g}^{-1}$. Já Vilhalva et al. (2011), em pães à base de farinha de mandioca, relataram

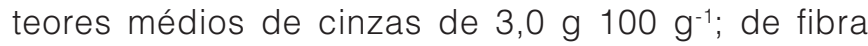
insolúvel, de 2,0 a 15,0 g $100 \mathrm{~g}^{-1}$, e de valor calórico, de 200 e $320 \mathrm{kcal} 100 \mathrm{~g}^{-1}$. Estas diferenças são resultantes dos diferentes tipos de subprodutos utilizados, os quais, consequentemente, apresentam composições variadas.

De acordo com os teores de lipídios, as amostras enquadram-se nos valores estabelecidos pela legislação para alimentos sólidos com baixo teor de gorduras totais, com valores inferiores a $3 \mathrm{~g}$ por porção (50 g) (BRASIL, 2012). O consumo de uma porção de $50 \mathrm{~g}$ (1,5 fatia de pão de fôrma) de P2 fornece, aproximadamente, 0,27 g de extrato etéreo. Assim, constata-se que o pão elaborado com a adição de farinha mista apresenta baixo valor de extrato etéreo. De acordo com os teores de proteínas nos

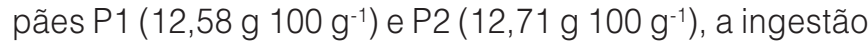
de uma porção de P1 e P2 fornece 6,29 g e 6,36 g de proteínas, respectivamente.

Estes teores atendem a, aproximadamente, 13\% da recomendação diária de proteínas, considerando-se que as necessidades diárias de um adulto do sexo masculino (70 kg) são de $50 \mathrm{~g}$ proteína dia-1 (BRASIL, 2005). Segundo a Agência Nacional de Vigilância Sanitária (BRASIL, 2012), um alimento é considerado fonte de proteína quando atende à condição de, no mínimo, $6 \mathrm{~g}$ de proteína por porção, sendo que as quantidades de aminoácidos essenciais da proteína adicionada ao alimento devem atender às condições estabelecidas.

Em pães elaborados com farinha mista de trigo e quinoa, Borges et al. (2013) relataram teores de proteínas

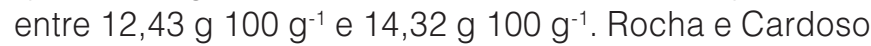
Santiago (2009) observaram teores de proteínas, nos pães elaborados com casca de baru, entre 12,97 e 14,13 g $100 \mathrm{~g}^{-1}$, e Bastos et al. (2014) encontraram, nos pães com farinha

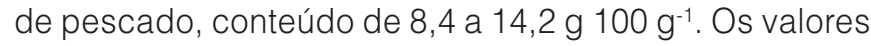
de proteína nos dois pães estudados neste trabalho (12,58 e 12,71 g $100 \mathrm{~g}^{-1}$ para P1 e P2, respectivamente) estão próximos aos encontrados por Borges et al. (2013), por Rocha e Cardoso Santiago (2009) e por Bastos et al. (2014).

Em relação aos teores de fibra alimentar total, que variaram de 5,84 a 7,96 g $100 \mathrm{~g}^{-1}$, observou-se aumento significativo entre as duas formulações, com o acréscimo da farinha mista. O mesmo foi observado para os valores de fibra insolúvel e solúvel, que foram maiores nos pães P2.

Os teores de fibra total deste trabalho foram superiores aos de Rocha e Cardoso Santiago (2009), em pães à base de

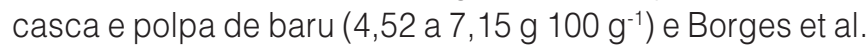
(2013), em pães à base de farinha mista de trigo e quinoa (3,21 a 4,36 $\left.\mathrm{g} 100 \mathrm{~g}^{-1}\right)$. Novamente, essas diferenças são devidas aos constituintes presentes na elaboração dos pães. O pão P2 pode ser classificado como fonte de fibra, pois a legislação brasileira exige um mínimo de 2,5 g por 
porção (alimentos sólidos) para tal classificação. O IOM (2005) recomenda a ingestão de 25 a $38 \mathrm{~g}$ de fibras por dia. Assim, a ingestão de uma porção (50 g) do P2, por exemplo, fornece, aproximadamente, $4 \mathrm{~g}$ de fibras, o que supre em $10 \%$ a $16 \%$ a recomendação diária.

De acordo com a Tabela Brasileira de Composição de Alimentos da UNICAMP (2011), o pão de fôrma integral clássico tem 34,70 g $100 \mathrm{~g}^{-1}$ de umidade, 9,40 g $100 \mathrm{~g}^{-1}$ de proteína, 3,70 g $100 \mathrm{~g}^{-1}$ de lipídios, 49,90 g $100 \mathrm{~g}^{-1}$ de carboidratos, 2,30 g $100 \mathrm{~g}^{-1}$ de cinzas e 6,9 $\mathrm{g} 100 \mathrm{~g}^{-1}$ de fibra alimentar. Neste estudo, os tratamentos P1 e P2 obtiveram médias menores de umidade, lipídeos, carboidratos e cinzas, e somente o P2 obteve valores maiores de fibras e proteínas (Tabela 3).

Para os valores de pH, entre os pães P1 e P2, houve uma variação significativa, em que se observou que o tratamento sem a adição de FM apresentou maior $\mathrm{pH}$ (Tabela 3). O caráter ácido da farinha mista adicionada ao pão P2 foi responsável por agregar essa característica. Barbosa et al. (2013), caracterizando pão de fôrma enriquecido com farinha de castanha de caju, observaram que, para o pão de fôrma sem substituição da farinha de trigo pela farinha de castanha de caju, os valores de $\mathrm{pH}$ foram maiores $(5,14)$ do que os pães que receberam a substituição (5,04). Ziglio et al. (2007), elaborando pães com a adição de farinha de sabugo de milho, também observaram uma diminuição discreta dos valores de $\mathrm{pH}$, à medida que era adicionada esta farinha. $\mathrm{O}$ tratamento que apresentou maior acidez titulável foi P2 (Tabela 3). As análises de $\mathrm{pH}$ e acidez titulável são importantes para verificar a qualidade microbiológica do produto.

O teor de compostos fenólicos no P2 foi até cerca de duas vezes mais elevado em relação ao P1 (Tabela 3). Moura et al. (2009) elaboraram pães de fôrma com adição de diferentes concentrações de semente de linhaça

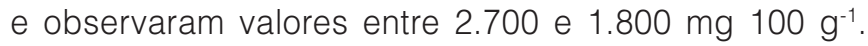
Esses teores são superiores aos encontrados nos pães do presente estudo. O teor de compostos fenólicos acima de $1 \%$ é considerado nocivo à saúde (CORRÊA et al., 2000) e os pães P1 e P2 apresentaram teores de compostos fenólicos totais abaixo do valor considerado nocivo à saúde. Portanto, nesse percentual encontrado, são considerados benéficos a saúde, uma vez que atuam como antioxidantes, prevenindo a ocorrência de algumas doenças, como as vasculares e coronarianas.

As calorias registradas nos pães P1 e P2 não apresentaram diferenças significativas entre si (Tabela 3). Porém, houve um pequeno aumento no valor calórico no pão, com o acréscimo da farinha mista. Barbosa et al. (2013), desenvolvendo pães de fôrma enriquecidos com farinha de castanha de caju, relataram uma variação calórica entre os tratamentos de 296, 51 e 336,69 kcal $100 \mathrm{~g}^{-1}$. Portanto, os pães do presente trabalho são menos calóricos.
De acordo com a ANVISA (BRASIL, 2012), "alimento fonte de vitaminas e minerais" é aquele que fornece, no mínimo, 15\% da ingestão diária recomendada (RDI) de referência, por porção de alimento sólido, e "alimento rico em minerais e vitaminas" como aquele que contém, no mínimo, 30\% da IDR de referência, por porção de alimento sólido.

Verifica-se, pelos dados da Tabela 4, que uma porção de $50 \mathrm{~g}$ de P1 e P2 atende à recomendação de ingestão diária (RDI) para adultos de 15,86\% e 17,71\% de fósforo; 2,66\% e 3,94\% de potássio; 11,92\% e 13,85\% de magnésio; 3,33\% e 5,0\% de cobre; 36,9\% e 40\% de manganês; $17,64 \%$ e 18,79\% de zinco, e 25,39\% e 22,5\% de ferro, respectivamente (BRASIL, 2005). Portanto, P1 e P2 são fonte de fósforo, zinco e ferro, e ricos em manganês.

Bastos et al. (2014), estudando pães de fôrma elaborados com subprodutos do pescado, encontraram níveis superiores para o mineral Ca (2,5 a 350 mg $100 \mathrm{~g}^{-1}$ ) e semelhantes aos do presente estudo para os minerais

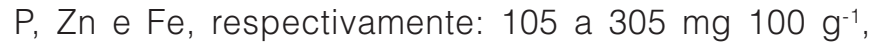
1,7 a 2,8 mg $100 \mathrm{~g}^{-1}$ e 5,1 a 6,4 mg $100 \mathrm{~g}^{-1}$

Não foi encontrado o mineral enxofre em nenhuma das duas formulações e o cálcio foi observado apenas no pão com adição de 3\% de FM (Tabela 4).

O volume específico encontrado para o P2 $\left(2,06 \mathrm{~cm}^{3} \mathrm{~g}^{-1}\right)$ foi menor que o observado para o P1 $\left(4,84 \mathrm{~cm}^{3} \mathrm{~g}^{-1}\right)$ (Tabela 5). Gandra et al. (2008) obtiveram valores de volumes específicos de 3,77 e 4,40 $\mathrm{cm}^{3} \mathrm{~g}^{-1} \mathrm{em}$ pães de fôrma enriquecidos com fibras e adicionados de lipase e monoglicerídeos. Bonet et al. (2006) relataram volumes específicos variando de 3,41 a $4,42 \mathrm{~cm}^{3} \mathrm{~g}^{-1}$, em pães adicionados de glicose oxidase.

O volume específico encontrado por Rocha e Cardoso Santiago (2009) apresentou intervalo de 3,84 a 4,09 $\mathrm{cm}^{3} \mathrm{~g}^{-1}$, em pães de fôrma elaborados com

Tabela 4. Valores médios da composição mineral dos pães de fôrma integrais com adição de farinha de derivados do mamão.

\begin{tabular}{cccc}
$\begin{array}{c}\text { Minerais } \\
\left.\text { (mg } \mathbf{1 0 0} \mathbf{~ g}^{-1}\right)\end{array}$ & $\mathbf{P 1}^{1}$ & $\mathbf{P 2}^{\mathbf{2}}$ & $\begin{array}{c}\mathbf{R D I}^{3} \\
\mathbf{m g ~ d i a}^{-1} \mathbf{)}\end{array}$ \\
\hline $\begin{array}{c}\text { Fósforo } \\
\text { Potássio }\end{array}$ & $222,00 \pm 9,8^{\mathrm{b}}$ & $248,00 \pm 9,80^{\mathrm{a}}$ & 700,0 \\
Cálcio & - & $0,01 \pm 0,00$ & 1000,0 \\
Magnésio & $62,00 \pm 4,00^{\mathrm{b}}$ & $72,00 \pm 7,50^{\mathrm{a}}$ & 260,0 \\
Enxofre & - & - & - \\
Boro & $0,15 \pm 0,00$ & $0,15 \pm 0,00^{\mathrm{ns}}$ & - \\
Cobre & $0,06 \pm 0,01^{\mathrm{b}}$ & $0,09 \pm 0,01^{\mathrm{a}}$ & 0,9 \\
Manganês & $1,70 \pm 0,14$ & $1,84 \pm 0,14^{\mathrm{ns}}$ & 2,3 \\
Zinco & $2,47 \pm 0,10$ & $2,63 \pm 0,25^{\mathrm{ns}}$ & 7,0 \\
Ferro & $7,11 \pm 0,19^{\mathrm{a}}$ & $6,3 \pm 0,21^{\mathrm{b}}$ & 14,0 \\
\hline
\end{tabular}

ns_ não significativo, a $5 \%$ de probabilidade $(n=6) ;{ }^{1} P 1$ - controle; ${ }^{2} \mathrm{P} 2$ - pão com adição de $3 \%$ de farinha mista (FM); ${ }^{3}$ Recomendação diária para adultos (BRASIL, 2005) 
Tabela 5. Valores médios de volume específico, peso, perda de massa, densidade, textura e cor dos pães integrais com adição de farinha de derivados do mamão.

\begin{tabular}{|c|c|c|}
\hline Parâmetros & P1 ${ }^{1}$ & $\mathbf{P}^{2}{ }^{2}$ \\
\hline $\begin{array}{l}\text { Volume específico } \\
\qquad\left(\mathrm{cm}^{3} \mathrm{~g}^{-1}\right)\end{array}$ & $4,84 \pm 0,24{ }^{a}$ & $2,06 \pm 0,20^{b}$ \\
\hline Peso (g) & $211,52 \pm 1,75^{b}$ & $217,65 \pm 2,01^{a}$ \\
\hline $\begin{array}{c}\text { Perda de massa } \\
\text { (g) }\end{array}$ & $38,48 \pm 1,75^{a}$ & $29,47 \pm 6,64^{b}$ \\
\hline Densidade $\left(\mathrm{g} \mathrm{cm}^{-3}\right)$ & $0,21 \pm 0,01^{b}$ & $0,48 \pm 0,04^{a}$ \\
\hline Textura (N) & $0,55 \pm 0,10^{b}$ & $5,49 \pm 0,33^{a}$ \\
\hline Cor $a^{*}$ & $3,47 \pm 0,07^{b}$ & $5,47 \pm 0,07^{a}$ \\
\hline$b^{*}$ & $16,91 \pm 0,23 \mathrm{~b}$ & $20,01 \pm 0,32{ }^{a}$ \\
\hline$L^{*}$ & $73,84 \pm 0,34{ }^{a}$ & $56,74 \pm 0,25^{b}$ \\
\hline
\end{tabular}

Médias seguidas pela mesma letra, na linha, não diferem entre si pelo Teste Tukey, a $5 \%$ de probabilidade $(n=6) ;{ }^{1} \mathrm{P} 1$ - controle; ${ }^{2} \mathrm{P} 2$ - pão com adição de $3 \%$ de farinha mista (FM).

polpa e casca de baru. A adição de farinha de "okara" reduziu o volume específico do pão de fôrma no estudo realizado por Silva et al. (2009). Os pães elaborados por esses autores, de aproximadamente $360 \mathrm{~g}$ de massa, após o forneamento, apresentaram valores médios de $5,41,4,96,4,76$ e 2,97 $\mathrm{cm}^{3} \mathrm{~g}^{-1}$ de volume específico, com 0\%, 5\%, 10\% e 15\% de adição de farinha de "okara", respectivamente. A adição de glúten, de agentes oxidantes, de alguns emulsificantes e de enzimas melhora a retenção dos gases e, consequentemente, o volume final (GANDRA et al., 2008). Os resultados encontrados neste trabalho (Tabela 5) sugerem uma interação entre os componentes da farinha de trigo e da farinha mista, resultando volumes específicos inferiores nos produtos com a farinha mista.

Para a análise de peso e perda de massa, houve diferença significativa entre os tratamentos P1 e P2, tendo os valores médios dos pesos de 211,25 e 217,65 g, e das perdas de 38,48 e 29,47 g, para os tratamentos P1 e P2, respectivamente. Essa diferença pode ter ocorrido devido à adição da farinha mista que, provavelmente, tem maior capacidade de absorção de água e, portanto, menor quantidade de água livre disponível na massa. Assim, durante o forneamento, a perda de água foi menor no tratamento P2 que no P1 e os pães P2 ficaram mais pesados que os pães $\mathrm{P} 1$.

Em relação à densidade, houve diferença significativa entre os tratamentos, sendo que os pães P2 resultaram em pães mais densos, pelo fato de serem mais pesados e ocuparem volumes menores. Rocha e Cardoso Santiago (2009) apresentaram, para pães de fôrma elaborados com polpa e casca de baru, valores de densidade entre 0,22 e $0,57 \mathrm{~g} \mathrm{~cm}^{-3}$, e obtiveram resultados semelhantes aos do presente estudo, que foram de 0,21 e 0,48 $\mathrm{g} \mathrm{cm}^{-3}$, para o controle P1 e o tratamento $\mathrm{P} 2$, respectivamente. Os consumidores têm preferência por pães mais leves, portanto, pães com menor densidade são mais aceitos.
Os resultados das análises de textura que avaliaram a firmeza foram de 0,55 e 5,49 N, para os tratamentos $\mathrm{P} 1$ e $\mathrm{P} 2$, respectivamente. Observa-se que houve grande aumento na firmeza do pão ao adicionar a farinha mista (Tabela 5). Este resultado ocorreu devido ao enfraquecimento do glúten, proveniente da farinha de trigo.

O aumento da dureza, pela adição de farinha mista de casca e semente de mamão, provavelmente está relacionado com o aumento da densidade e a redução do volume dos pães, causando maior compactação de sua estrutura. Deve-se levar em conta que as farinhas obtidas das frações do mamão são ricas em fibra, o que também contribui para uma firmeza maior do pão.

A textura para produtos panificados mostra-se dependente da formulação, no que tange a qualidade da farinha; quantidade de açúcares, gorduras, emulsificantes, enzimas e mesmo a adição de glúten e melhoradores de farinha; umidade da massa, e conservação (ESTELLER; LANNES, 2005). Geralmente, pães com altos teores de fibras, como observado no presente estudo, apresentam textura mais firme (ALPASLAN; HAYTA, 2006; OLIVEIRA et al., 2007).

Os valores de $L^{*}$, que indicam a luminosidade na faixa de 100 (branco) a 0 (negro), diferiram entre as amostras de pão P1 e P2 (Tabela 5). Foi possível observar que a amostra com adição de FM (3\%) tendeu ao escurecimento, quando comparada com o controle.

A coordenada $a^{*}$, que indica a variação de verde (-60) a vermelho (+60), é um parâmetro importante para o estudo de escurecimento, pois a cor marrom, resultante da degradação dos açúcares ou reações enzimáticas, representa uma combinação do verde e vermelho. Um maior escurecimento é representado por um tom mais avermelhado, ou seja, maior valor de $a^{\star}$. A coordenada $\mathrm{b}^{\star}$, relacionada ao eixo que varia de azul (-60) a amarelo (+60), demonstrou variações entre os pães P1 e P2, e este último, situando-se na faixa positiva e com maior tendência para o amarelo, quando comparado a P1. O pão integral com adição de 3\% (P2) de farinha mista alcançou coloração mais intensa de amarelo-castanho que o pão integral sem adição de farinha mista.

Resultados semelhantes foram obtidos por Borges et al. (2013), ao utilizarem farinha mista de trigo e quinoa, na elaboração de pães de fôrma. Estes autores verificaram diferença significativa da cor entre o controle (sem farinha de quinoa) e o tratamento F15 (com 15\% de farinha quinoa). O tratamento F15 alcançou maior tendência ao amarelo e ao vermelho, devido à presença de quinoa na formulação, indicando que a presença de pigmentação nessa matéria-prima interferiu na cor dos pães.

\section{Conclusão}

Os resultados permitem concluir que houve melhorias no valor nutricional dos pães de fôrma integral com a adição da farinha mista de casca e semente de mamão 
Preparação, caracterização e análise sensorial de pão integral enriquecido com farinha de subprodutos do mamão Santos, C. M. et al.

da cultivar Havaí, promovidas pelo aumento dos teores de fibra alimentar total e proteínas, e pelos baixos teores de lipídeos. Apesar da diminuição da qualidade tecnológica dos pães de fôrma integral (cor e firmeza), o pão integral com adição de $3 \%$ de farinha mista obteve boa aceitação pelos provadores. Os benefícios pelo aumento no teor de fibras podem compensar a diminuição da qualidade, além de utilizar os subprodutos do mamão na elaboração de produtos de panificação e evitar o seu descarte no meio ambiente.

\section{Agradecimentos}

Os autores agradecem à FAPEMIG, à CAPES e ao CNPq pelo apoio financeiro.

\section{Referências}

ALPASLAN, M.; HAYTA, M. The effects of flaxseed, soy and corn flours on the textural and sensory properties of a bakery product. Journal of Food Quality, v. 29, n. 6, p. 617-627, 2006. http:// dx.doi.org/10.1111/j.1745-4557.2006.00099.x.

BARBOSA, B. E. M.; BRONDANI, F. M. M.; FARIAS, G. J. Caracterização físico-química do pão de forma enriquecido com farinha de castanha de caju (Anacardium occidentale L.).

Revista Científica FAEMA, v. 4, n. 2, p. 49-64, 2013.

BASTOS, S. C.; TAVARES, T.; PIMENTA, M. E. S. G.; LEAL, R.; FABRICIO, L. F.; PIMENTA, C. J.; NUNES, C. A.; PINHEIRO, A. C. $M$. Fish filleting residues for enrichment of wheat bread: chemical and sensory characteristics. Journal of Food Science and Technology, v. 51, n. 9, p. 2240-2245, 2014. PMid:25190890. http://dx.doi.org/10.1007/s13197-014-1258-1.

BONET, A.; ROSELL, C. M.; CABALLERO, P. A.; GÓMEZ, M.; PÉREZ-MUNUERA, I.; LLUCH, M. A. Glucose oxidase effect on dough rheology and bread quality: a study from macroscopic to molecular level. Food Chemistry, v. 99, n. 2, p. 408-415, 2006. http://dx.doi.org/10.1016/j.foodchem.2005.07.043.

BORGES, J. T. S.; VIDIGAL, J. G.; SILVA, N. A. S.; PIROZI, M. R.; PAULA, C. D. Caracterização físico-química e sensorial de pão de forma contendo farinha mista de trigo e quinoa. Revista Brasileira de Produtos Agroindustriais, v. 15, n. 3, p. 305-319, 2013. http://dx.doi.org/10.15871/1517-8595/rbpa.v15n3p305-319.

BRASIL. Agência Nacional de Vigilância Sanitária. Resolução RDC $n^{\circ} 269$, de 22 de setembro de 2005. Regulamento técnico sobre a ingestão diária recomendada (IDR) para proteínas, vitaminas e minerais. Diário Oficial [da] República Federativa do Brasil, Brasília, DF, 23 set. 2005. Disponível em: <http://portal.anvisa. gov.br/documents/33916/394219/RDC_269_2005.pdf/2e95553ca482-45c3-bdd1-f96162d607b3 >. Acesso em: 12 jan. 2014.

BRASIL. Agência Nacional de Vigilância Sanitária. Resolução RDC $n^{\circ} 54$, de 12 de novembro de 2012. Regulamento técnico sobre informação nutricional complementar. Diário Oficial [da] República Federativa do Brasil, Brasília, DF, 13 nov. 2012.
Disponível em: <http://bvsms.saude.gov.br/bvs/saudelegis/ anvisa/2012/rdc0054_12_11_2012.html>. Acesso em: 12 jan. 2014.

CORRÊA, A. D.; ABREU, C. M. P.; SANTOS, C. D.; RIBEIRO, L. J. Determinação de alguns constituintes químicos de interesse nutricional da fruta-de-lobo (Solanum lycocarpum St.Hil.). Ciência e Agrotecnologia, v. 24, n. 1, p. 130-135, 2000.

ESTELLER, M. S.; LANNES, S. C. S. Parâmetros complementares para fixação de identidade e qualidade de produtos panificados. Ciência e Tecnologia de Alimentos, v. 25, n. 4, p. 802-806, 2005. http://dx.doi.org/10.1590/S0101-20612005000400028.

FERREIRA, S. M. R.; OLIVEIRA, P. V.; PRETTO, D. Parâmetros de qualidade do pão francês. Boletim do Centro de Pesquisas e Processamento de Alimentos, v. 19, n. 2, p. 301-318, 2001.

FIGUEIREDO, S. M.; RESENDE, V. A.; DIAS, C.; RIBEIRO, L. D. Fibras alimentares: combinações de alimentos para atingir meta de consumo de fibra solúvel/dia. e-Scientia, v. 2, n. 1, p. $1-18,2009$

GANDRA, K. M.; DEL BIANCHI, M.; GODOY, V. P.; QUEIROZ, F. P. C.; STEEL, C. J. Aplicação de lipase e monoglicerídeo em pão de forma enriquecido com fibras. Ciência e Tecnologia de Alimentos, v. 28, n. 1, p. 182-192, 2008. http://dx.doi.org/10.1590/ S0101-20612008000100027.

GENNADIOS, A.; WELLER, C. L.; HANNA, M. A.; FRONING, G. W. Mechanical and barrier properties of egg albumen films. Journal of Food Science, v. 61, n. 3, p. 585-589, 1996. http:// dx.doi.org/10.1111/j.1365-2621.1996.tb13164.x.

INSTITUTE OF MEDICINE OF THE NATURAL ACADEMIES - IOM. Dietary reference intakes for energy, carbohydrate, fiber, fat, fatty acids, cholesterol, protein, and amino acids. Washington: National Academies, 2005.

INSTITUTO ADOLFO LUTZ - IAL. Normas analíticas, métodos químicos e físicos para análises de alimentos. 3. ed. São Paulo: IAL, 2005.

KAJISHIMA, S.; PUMAR, M.; GERMANI, R. Elaboração de pão francês com farinha enriquecida de sulfato de cálcio. Boletim do Centro de Pesquisa de Processamentos de Alimentos, v. 19, n. 2, p. 157-168, 2001.

LATIMER JUNIOR, G. W. (Ed.). Official methods of analysis. 19th ed. Gaithersburg: AOAC, 2012.

MAIA, J. D.; BARROS, M. O.; CUNHA, V. C. M.; SANTOS, G. R.; CONSTANT, P. B. L. Estudo da aceitabilidade do pão de forma enriquecido com farinha de resíduo da polpa de coco. Revista Brasileira de Produtos Agroindustriais, v. 17, n. 1, p. 1-9, 2015. http://dx.doi.org/10.15871/1517-8595/rbpa.v17n1p1-9.

MALAVOltA, E.; VITTI, G. C.; OLIVEIRA, A. S. Avaliação do estado nutricional das plantas. Piracicaba: Potafós, 1997.

MOURA, N. C.; CANNIAT-BRAZACA, S. G.; SILVA, A. G. Elaboração de rótulo nutricional para pães de forma com adição de diferentes 
Preparação, caracterização e análise sensorial de pão integral enriquecido com farinha de subprodutos do mamão Santos, C. M. et al.

concentrações de linhaça (Linum usitatissimum). Alimentos e Nutrição, v. 20, n. 1, p. 149-155, 2009.

OLIVEIRA, N. M. A. L.; MACIEL, J. F.; LIMA, A. S.; SALVINO, E. M.; MACIEL, C. E. P.; MENEZES, D. P.; OLIVEIRA, N.; FARIAS, L. R. G. Características físico-químicas e sensoriais de pão de forma enriquecido com concentrado proteico de soro de leite e carbonato de cálcio. Revista do Instituto Adolfo Lutz, v. 70, n. 1, p. 16-22, 2011.

OLIVEIRA, T. M.; PIROZI, M. R.; BORGES, J. T. S. Elaboração de pão de sal utilizando farinha mista de trigo e linhaça. Alimentos e Nutrição, v. 18, n. 2, p. 141-150, 2007.

PINHEIRO, A. C. M.; NUNES, C. A.; VIETORIS, V. SensoMaker: a tool for sensorial characterization of food products. Ciência e Agrotecnologia, v. 37, n. 3, p. 199-201, 2013. http://dx.doi. org/10.1590/S1413-70542013000300001.

PORTE, A.; SILVA, E. F.; ALMEIDA, V. D. S. A.; SILVA, X. S.; PORTE, L. H. M. Propriedades funcionais tecnológicas das farinhas de sementes de mamão (carica Papaya) e de abóbora (cucurbita $s p)$. Revista Brasileira de Produtos Agroindustriais, v. 13, n. 1, p. 91-96, 2011. http://dx.doi.org/10.15871/1517-8595/rbpa. v13n1p91-96.

R CORE TEAM. R: a language and environment for statistical computing. Vienna: R Foundation for Statistical Computing, 2013. Disponível em: <http://www.R-project.org>. Acesso em: 5 set. 2013.

ROCHA, L. S.; CARDOSO SANTIAGO, R. A. Implicações nutricionais e sensoriais da polpa e casca de baru (Dipterix Alata vog.) na elaboração de pães. Ciência e Tecnologia de Alimentos, v. 29, n. 4, p. 820-825, 2009. http://dx.doi.org/10.1590/ S0101-20612009000400019.

SANTOS, C. M.; ABREU, C. M. P.; FREIRE, J. M.; QUEIROZ, E. R.; MENDONÇA, M. M. Chemical characterization of the flour of peel and seed from two papaya cultivars. Food Science and Technology, v. 34, n. 2, p. 353-357, 2014. http://dx.doi. org/10.1590/fst.2014.0048.

SILVA, L. H.; PAUCAR-MENACHO, L. M.; VICENTE, C. A.; SALES, A. S.; STEEL, C. J. Desenvolvimento de pão de fôrma com a adição de farinha de "okara". Brazilian Journal of Food Technology, v. 12, n. 4, p. 315-322, 2009. http://dx.doi. org/10.4260/BJFT2009800900027.

STORCK, C. R.; NUNES, G. L.; OLIVEIRA, B. B.; BASSO, C. Folhas, talos, cascas e sementes de vegetais: composição nutricional, aproveitamento na alimentação e análise sensorial de preparações. Ciência Rural, v. 43, n. 3, p. 537-543, 2013. http://dx.doi.org/10.1590/S0103-84782013000300027.

UCHÔA THOMAZ, A. A.; SOUSA, E. C.; LIMA, A. D.; LIMA, R. M. T.; FREITAS, P. A. P.; SOUSA, M. A. M.; THOMAZ, J. C. D. A.; CARIOCA, J. O. B. Elaboração e aceitabilidade de produtos de panificação enriquecidos com semente de goiaba (Psidium uajava) em pó. HoLOS, v. 5, p. 199-210, 2014. http://dx.doi. org/10.15628/holos.2014.1895.

UNIVERSIDADE ESTADUAL DE CAMPINAS - UNICAMP. Tabela Brasileira de Composição de Alimentos - TACO. Versão 4. Campinas: UNICAMP, 2011. Disponível em: < http://www.cfn. org.br/wp-content/uploads/2017/03/taco_4_edicao_ampliada_e_ revisada.pdf >. Acesso em: 10 mar. 2015

VENTURINI, T.; BENCHUINAL, L. R.; BERTUAL, D. A.; ROSA, M. B. MEILLI. Estudo da secagem e extração de semente de mamão (Carica Papaya L.). Revista Eletrônica em Gestão Tecnologia Ambiental, v. 5, n. 5, p. 950-959, 2012.

VILHALVA, D. A. A.; SOARES JUNIOR, M.; MOURA, C. M. A.; CALIARI, M.; SOUZA, T. A. C.; SILVA, F. A. Aproveitamento da farinha de casca de mandioca na elaboração de pão de forma. Revista do Instituto Adolfo Lutz, v. 70, n. 4, p. 514-521, 2011.

WAKELING, I. N.; MACFIE, J. H. Designing consumer trials balanced for first and higher orders of carry-over effect when only a subset of k samples from t may be tested. Food Quality and Preference, v. 6, n. 4, p. 299-308, 1995. http://dx.doi. org/10.1016/0950-3293(95)00032-1.

ZIGLIO, B. R.; BEZERRA, J. R. M. V.; BRANCO, I. G.; BASTOS, R.; RIGO, M. Elaboração de pães com adição de farinha de sabugo de milho. Revista Ciências Exatas e Naturais, v. 9, n. 1, p. 116-128, 2007. 